\title{
Valorization of calcined kaolinitic clay used in high performance mortar
}

\author{
Mansour S M*, Ghernouti Y, Chaid R \\ University of M'Hamed Bougara, Dept. Civil Engineering, UR/MPE Lab., Avenue de l'indépendance, 35000, \\ Boumerdes, Algeria \\ * Corresponding Author: s.mansour@univ-boumerdes.dz
}

Received: 18-11-2019

Accepted: 04-02-2020

\begin{abstract}
In this work, an experimental investigation was carried out to evaluate the potential of an industrial pozzolan, the metakaolin, on the behavior of mortar. The aim is to use metakaolin as a $10 \%$ partial replacement of cement. Its effect on the physico-mechanical properties of the mortar has been analyzed. The results show that the incorporation of metakaolin decreases the density of the dried mortar and increases that of the wet mortar but these remain lower than those of the control mortar. Moreover, thermal analysis ATD / ATG shows that in the heat flow curve appears two endothermic peaks which correspond to the loss of mass of the cement pastes. Heat flux of these pastes increases when metakaolin is used into the cement. In addition, metakaolin increases the compressive and flexural strengths of wet and dry mortars by approaching without exceeding those of the control mortar. The use of metakaolin as a cement substitution has shown its potential to be a pozzolanic material that can offer economic, environmental and technical benefits.
\end{abstract}

Key words: Mortar; metakaolin; valorization; mechanical strengths.

\section{Introduction}

The construction sector is particularly emitter of greenhouse gases in particular $\mathrm{CO}_{2}$ released during the manufacture of Portland cement. To limit these discharges, with equivalent concrete performance, it is possible to replace a portion of the cement by certain additions such as pozzolans. The metakaolin produced from kaolin clays is one of these calcined pozzolans.

Metakaolin is a product known for several years and manufactured all over the world: France, Canada, United States, United Kingdom, Brazil, China, etc. It results from the calcination of clay, kaolinite, at temperatures between $600^{\circ} \mathrm{C}$ and $850^{\circ} \mathrm{C}$, according to the degree of order of the initial material (Badogiannis et al., 2005). It typically contains $50-55 \%$ silica $\mathrm{SiO}_{2}$ and $40-45 \%$ alumina $\mathrm{Al}_{2} \mathrm{O}_{3}$ and is highly reactive (Kostuch et al., 2000).

Calcination leads to a dehydroxylation reaction of the material, with a destruction of the initial crystalline structure leading to an amorphous nature of the material, which gives it a high pozzolanic power (Poon e al., 2001).

As a result, it is used to replace or add Portland cement to improve the performance of hardened concrete (Sabir et al., 2001; Tafraoui et al., 2009). Indeed, the incorporation of metakaolin into cements allows better hydration of anhydrous cement. It causes the appearance of a closed porosity favorable to the strength and durability of the cementitious matrices due to the formation of a larger amount of C-S-H and the lack of connection of the pores.

As such, the metakaolin used as partial substitution for Portland cement improves the mechanical performance of concretes and mortars (Mansour et al., 2012; Mansour et al., 2013; Madandoust and Mousavi, 2012).

Increasingly, a sustained interest is devoted to the use of cementitious materials, especially those which are rich in $\mathrm{SiO}_{2}$ and $\mathrm{Al}_{2} \mathrm{O}_{3}$, in the manufacture of hydraulic cements. Metakaolin is 
therefore a substitute for cement to increase its demand in the coming years, thanks to its high silica and alumina content, its advantageous technical properties, its low environmental impact and the fact that it is not an industrial byproduct. Indeed, it is not dependent on the technical and economic hazards of the manufacture of steel (slags) and silicon (silica fume), or the production of electricity (fly ash). The present work invests the effect of an active pozzolan, the metakaolin used as a cement substitution on the physico-mechanical properties of the mortar. A comparative experimental study was established between a control mortar without metakaolin and a mortar incorporating a $10 \%$ substitution rate of metakaolin.

\section{Experimental program}

\subsection{Materials}

The CEM I 52.5R cement of Lafarge in accordance with the NF EN 197-1 standard is preferably used because it contains a large amount of clinker (at least $95 \%$ by weight), has a high reactivity at an early age, and guarantees a 28-day minimum compressive strength of $52.5 \mathrm{MPa}$ on standardized mortars. Its specific surface area is $4200 \mathrm{~cm}^{2} / \mathrm{g}$ and its density is $3.15 \mathrm{~g} / \mathrm{cm}^{3}$. Siliceous sand according to the standard (EN 196-1) of 0/4 mm size with a specific density and water absorption of 2.6 and $1.2 \%$ respectively is used.

As an addition, the metakaolin having a $137.5 \mathrm{mg} \mathrm{Ca}(\mathrm{OH})_{2} / \mathrm{g}$ mineral activity according to NF P18-513 standard, a density of $2.54 \mathrm{~g} / \mathrm{cm}^{3}$ was chosen to replace a part of the cement for an economic and ecological purpose.

Metakaolin was obtained by calcination at $700^{\circ} \mathrm{C}$ for $5 \mathrm{~h}$ of crushed and sieved kaolin at $80 \mu \mathrm{m}$ from the region of Algeria-Tamazert (MILIA-Jijel). Generally, an optimum for kaolin clay calcinations recognized in literature is between $600^{\circ} \mathrm{C}$ and $900^{\circ} \mathrm{C}$ (Ambroise et al. 1986; Sayanam et al. 1989). After removal from the oven, the cooling of obtained product "metakaolin" was accomplished by placing it in a desiccator. The calcined product was then packaged in waterproof plastic bags.

Metakaolin is characterized by a specific surface area of $7550 \mathrm{~cm}^{2} / \mathrm{g}$ greater than that of the cement in order to increase the compactness of the mortar and its strength (Merabet and Belkacemi, 2003). The chemical compositions of metakaolin and cement are given in Table 1.

Table 1. Chemical composition of cement and metakaolin.

\begin{tabular}{|c|c|c|}
\hline Oxides (\%) & Cement & Metakaolin \\
\hline \hline $\mathrm{CaO}$ & 63.60 & 1.33 \\
\hline $\mathrm{SiO}_{2}$ & 19.85 & 58.32 \\
\hline $\mathrm{Al}_{2} \mathrm{O}_{3}$ & 4.80 & 35.36 \\
\hline $\mathrm{Fe}_{2} \mathrm{O}_{3}$ & 2.75 & 1.18 \\
\hline $\mathrm{MgO}$ & 1.45 & 0.21 \\
\hline $\mathrm{SO}_{3}$ & 3.45 & 0.31 \\
\hline $\mathrm{K}_{2} \mathrm{O}$ & 0.9 & 1.13 \\
\hline $\mathrm{Na}_{2} 0$ & 0.15 & 0.15 \\
\hline $\mathrm{LOI}$ & 2.20 & 2.01 \\
\hline
\end{tabular}

The X-ray diffraction mineralogical analysis and the scanning electron microscope SEM analysis show the mineral phases and the morphology of the metakaolin in Figure 1 and Figure 2 respectively.

The X-ray diffraction mineralogical analysis was carried out with the Philips PW 3710 diffractometer. It has a $\mathrm{Cu}$ anticathode with a $\mathrm{Ni}$ filter, so the wave length is $\lambda=1.54 \AA$. The step recording is carried out between 5 and $65^{\circ} 2 \theta$. Concerning the morphology of metakaolin, tests were carried out with an SEM field effect electron microscope (JEOL-JSM-6301F) from the INSA 
of RENNES on metakaolin powder previously covered with a thin layer of gold by vacuum metallization to obtain images in secondary electrons.

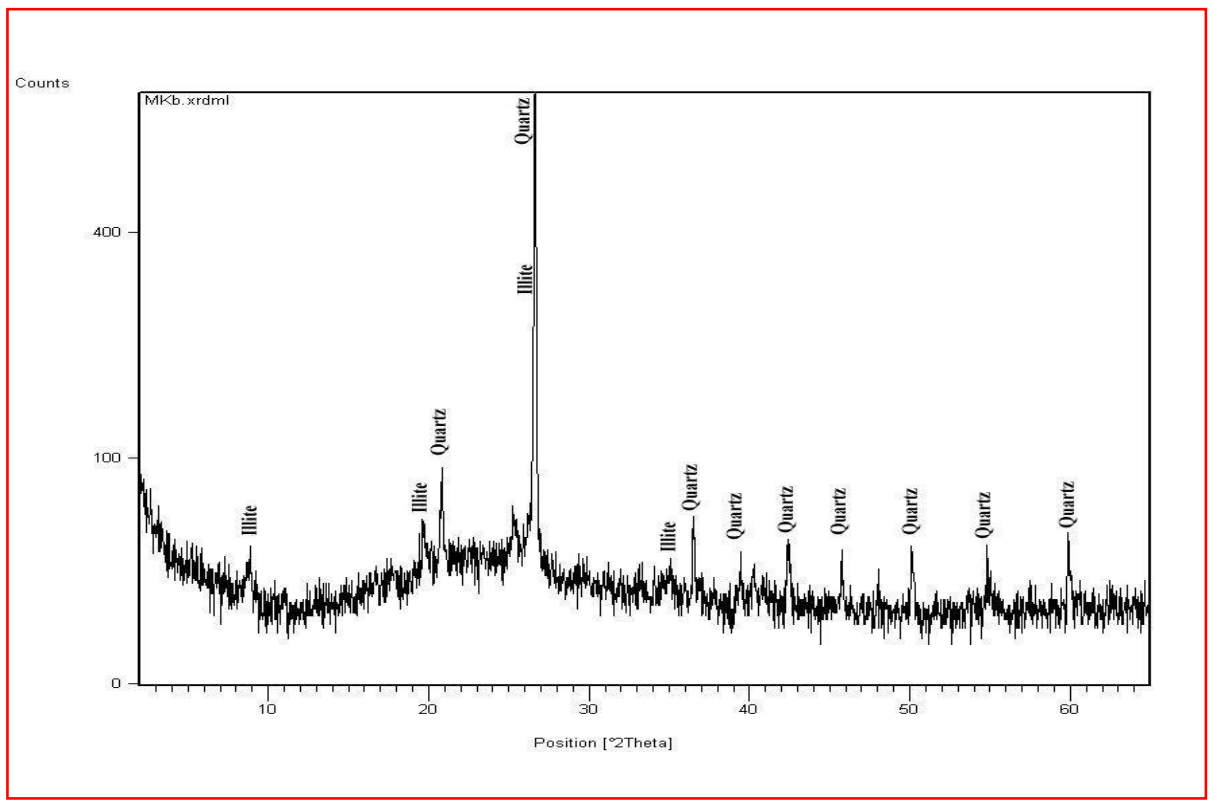

Fig. 1. Mineral phases of metakaolin by DRX.

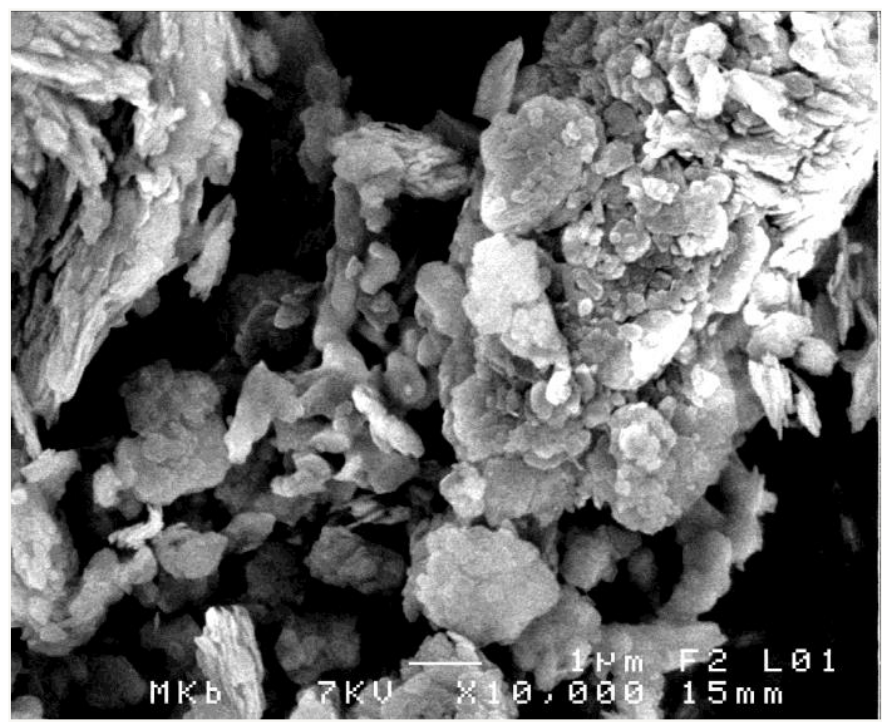

Fig. 2. Morphology of metakaolin by SEM (x10000).

\subsection{Preparation of samples analyzed by ATG / DSC}

Cement pastes (with or without metakaolin) are prepared and maintained in endogenous conditions in heat-sealed bags and then placed in a humid room at a temperature of $20^{\circ} \mathrm{C}$ and 95\% humidity, and are kept for 24 hours and 3 days.

After a suitable period of hydration, the samples are taken out of their bags and dried in an oven for 12 hours at $80^{\circ} \mathrm{C}$. until the day of the test, where they are finely ground and tested with the thermogravimetric analysis apparatus. The rate of rise in temperature is $5^{\circ} \mathrm{C} / \mathrm{min}$.

Thermogravimetric analysis was performed to evaluate the pozzolanic activity of metakaolin through the consumption of lime from prepared cement pastes. Lime consumption is evaluated by ATG/DSC at 1day and 3 days. Analysis thermogravimetric ATG/DSC is based on 
measurement, as a function of time and temperature, of mass variations of a sample subjected to an increase of temperature. The identification of hydrates is deduced by the decomposition temperature ranges being characteristic of solid phases studied (for example portlandite $\mathrm{Ca}(\mathrm{OH})_{2}$ and calcium silicate hydrated $\left.\mathrm{CSH}\right)$. The rate of lime consumed is deducted from the mass of residual portlandite shown by the mass loss recorded on the ATG/DSC diagram.

\subsection{Preparation of standardized mortars}

Standardized mortars were prepared in accordance with the standard NFP 15-403 (NF P 1996) with a constant water/binder ratio $=0.5$ and a sand-cement ratio $\mathrm{S} / \mathrm{C}=3$. The normal mortar described is made to using a HOBART mixer, in a five-liter tank meeting the specifications of the NFP 15-411 standard (NF P 1996).

A fixed rate of $10 \%$ metakaolin $\mathrm{MK}$ is chosen as substitution to replace part of cement. After curing and demolding after 24 hours, the $4 \times 4 \times 16 \mathrm{~cm}^{3}$ mortar specimens are stored in a dry room at $20^{\circ} \mathrm{C}$ and at $50 \%$ relative moisture.

In addition, other mortar specimens are kept in water at $20^{\circ} \mathrm{C}$ for measurements of mechanical compressive and flexural strengths NF P15-471-1 (EN 196-1) at 1, 3, 7, 14, 21 and 28 days of age.

\section{Results and discussion}

\subsection{XRD and SEM analysis}

Scanning electron microscope SEM analysis shows that the metakaolin is made up of particles in the form of lamellae and platelets. The observed shape of the particles facilitates the flow and prevents blockage of concrete.

From the X-ray diffraction mineralogical analysis of metakaolin, The X-ray analysis of perlite shows a bump which signifies a high content of amorphous silica and peaks which characterizes the crystalline phase such as quartz $\left(\mathrm{SiO}_{2}\right)$ and small amount of Illite $\left(\mathrm{K}_{2} \mathrm{O}, 2 \mathrm{H}_{2} \mathrm{O}\right.$, $2\left(\mathrm{Al}_{2}\left(\mathrm{Si}_{3} \mathrm{Al}\right) \mathrm{O}_{10} \mathrm{OH}\right)$.

\subsection{Chemical analysis}

The chemical analysis of metakaolin shows that it contains high rate of $58.32 \% \mathrm{SiO}_{2}$ of silica and $35.36 \% \mathrm{Al}_{2} \mathrm{O}_{3}$ of alumina compared to those of cement which are of the order of $19.85 \%$ and $4.80 \%$. This favors the pozzolanic reaction. The contribution of the additions to the development of the strength is mainly due to the filler effect, the dilution effect and the pozzolanic reaction with the portlandite $\mathrm{Ca}(\mathrm{OH})_{2}$ released during the hydration of the cement according to the reaction given by equation Eq.1:

$\mathrm{SiO}_{2}, \mathrm{Al}_{2} \mathrm{O}_{3}$ (Metakaolin) + $\mathrm{Ca}(\mathrm{OH})_{2}+$ water $\longrightarrow(\mathrm{C}-\mathrm{S}-\mathrm{H}),\left(\mathrm{C}_{4} \mathrm{AH}_{13}\right),\left(\mathrm{C}_{2} \mathrm{ASH}_{8}\right)$

(C-S-H): Hydrated calcium silicates, $\left(\mathrm{C}_{4} \mathrm{AH}_{13}\right)$ : hydrated calcium aluminates, $\left(\mathrm{C}_{2} \mathrm{ASH}_{8}\right)$ : Calcium silicate aluminates hydrated.

The products obtained are beneficial because they contribute to the development of mechanical strengths of the elaborated mortars.

\subsection{Exploitation of TGA/DSC thermal analysis results}

The analysis of thermogravimetric ATG curves depends on the relationship between temperature increase and mass variation as a result of dehydration, decomposition and oxidation. These curves can be divided into different important areas. Zone (I), between 100 and $300^{\circ} \mathrm{C}$, is attributed to the dehydration of C-S-H and ettringite. Zone (II), between 290 and $350^{\circ}$ $\mathrm{C}$, characterizes the decomposition of hydrated calcium silicate, hydrated calcium aluminate and chloroaluminate calcium. The third zone (III), ranging from 450 to $510^{\circ} \mathrm{C}$, is attributed to the 
dehydration of calcium hydroxide. The same curves show the relationship between the weight of the sample relative to the original weight of the sample and the applied temperature.

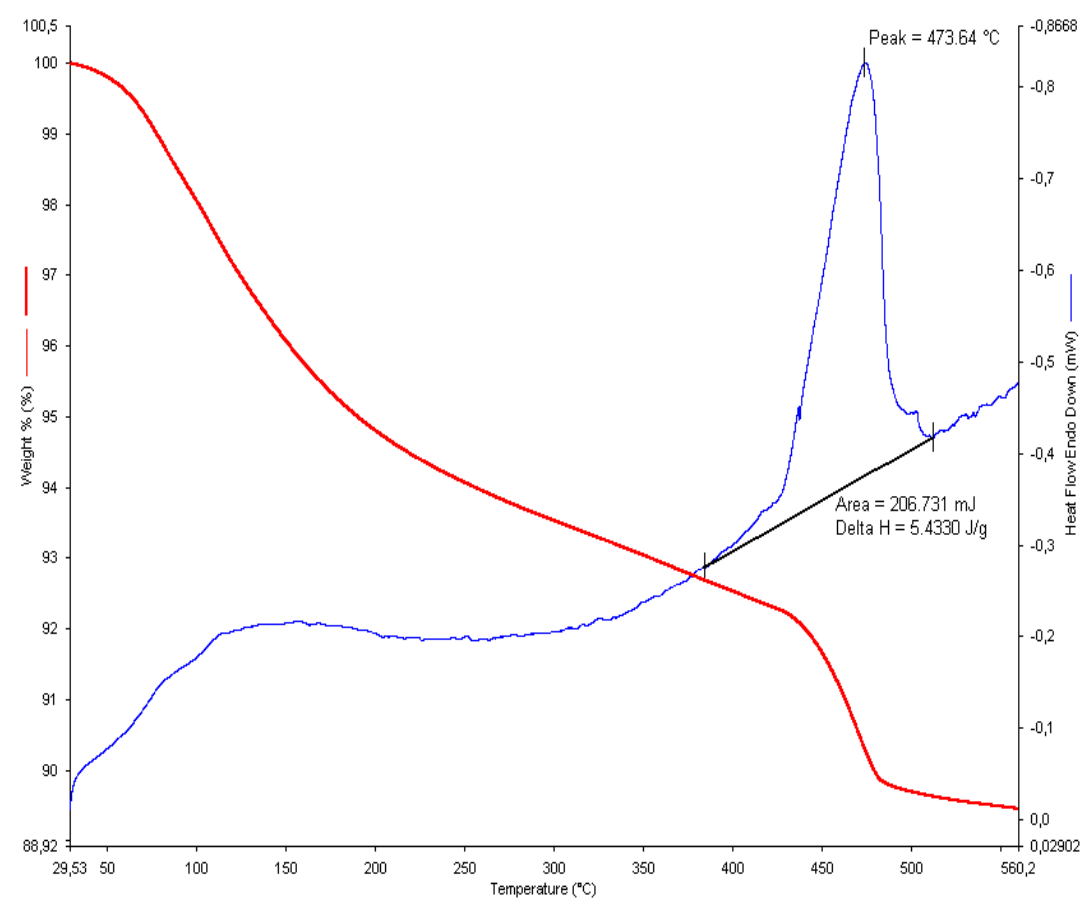

(a)

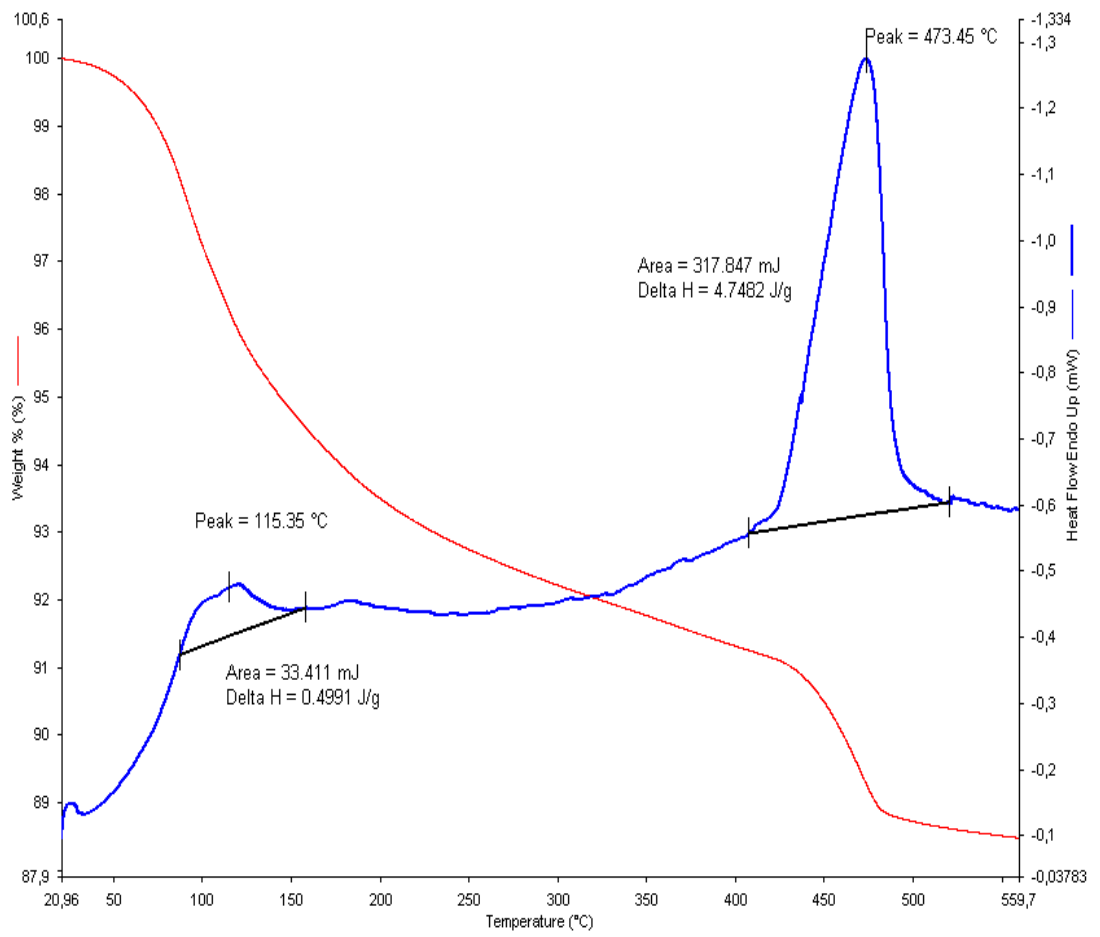

(b)

Fig. 3. ATD Thermogram of cement paste (a) - control, (b) - containing $10 \%$ MK after $24 \mathrm{~h}$ of hydration.

The evolutions of the profiles of the TG and thermal flux curves DSC of the pastes of cement mixtures with or without metakaolin are shown in Figure 3 and 4. Evolution of each of the curves is related to the initial mass of the studied sample. Each heat flux curve (DSC curve) has 
several endothermic peaks corresponding to mass losses (TG curve) for cement paste $24 \mathrm{~h}$ or 3 days of hydration.

It is clearly shown the existence of two marked endothermic peaks accompanied by mass losses and which spread over time from 1 day to 3 days in presence of metakaolin. This is a sign of reactivity of metakaolin.

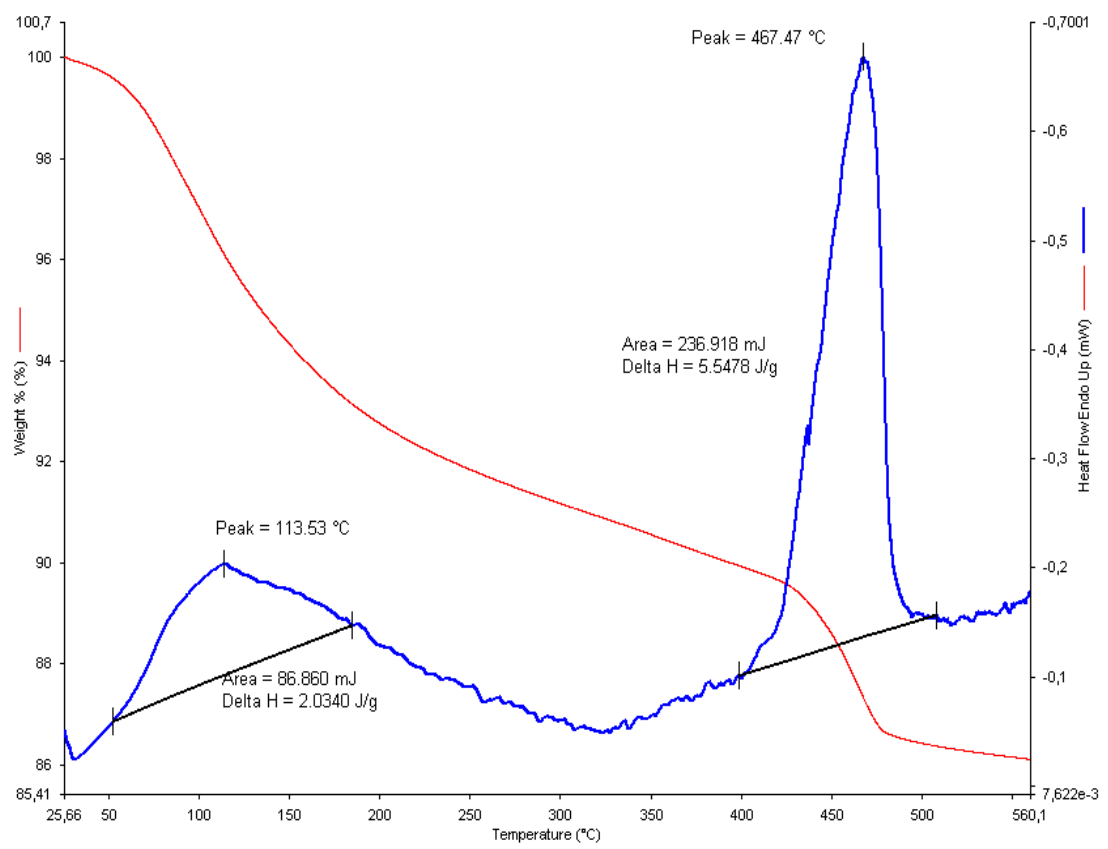

(a)

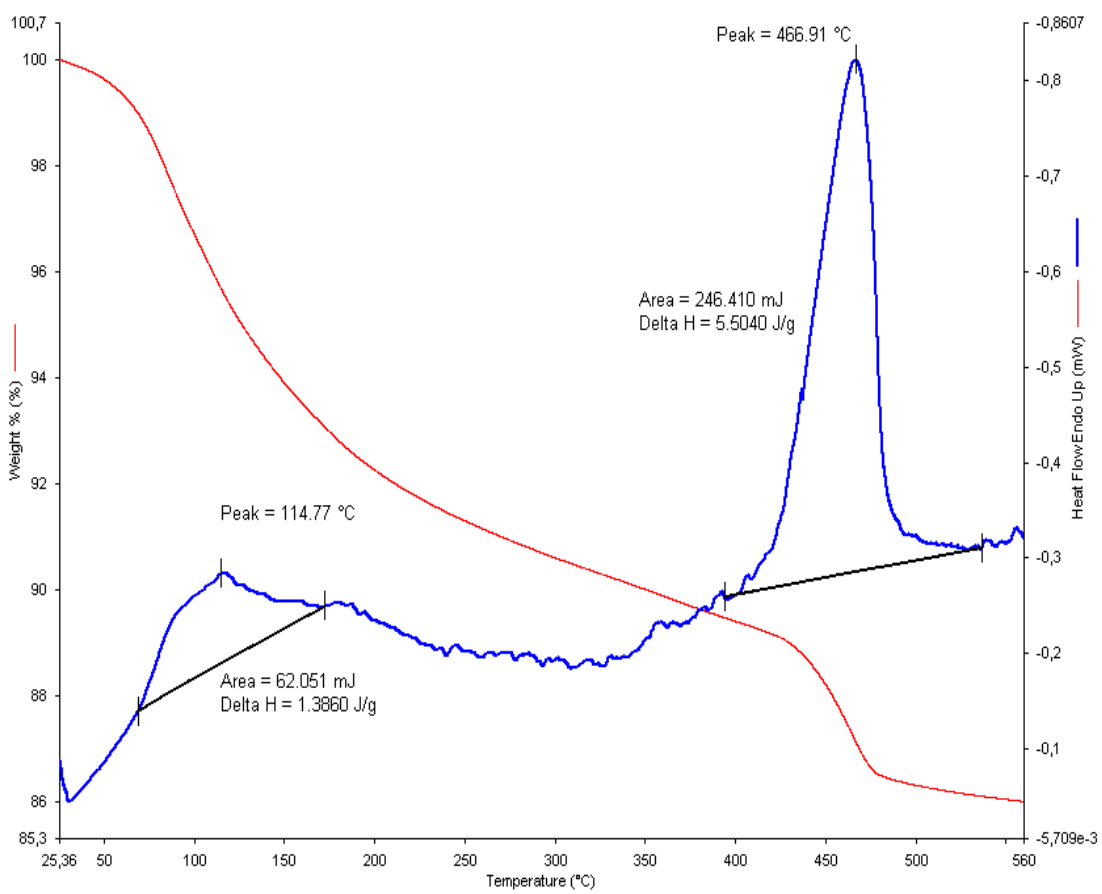

(b)

Fig. 4. ATD Thermogram of cement paste (a) - control, (b) - containing $10 \%$ MK after 3 days of hydration. 
The first peak centered on a temperature between $100^{\circ} \mathrm{C}$ and $200^{\circ} \mathrm{C}$ showing a loss of mass which corresponds to the dehydration of hydrated calcium silicates CSH indicating the presence of CSH hydrates (Rojas and Cabrera, 2002). The second endothermic peak centered at a temperature between $430^{\circ} \mathrm{C}$ and $500^{\circ} \mathrm{C}$ also showing a loss of mass which corresponds to the dehydration of calcium hydroxide $\mathrm{Ca}(\mathrm{OH})_{2}$. Between the two peaks, there is a portion between the temperature $250^{\circ} \mathrm{C}$ and $430^{\circ} \mathrm{C}$ showing a loss of mass corresponding to the decomposition of hydrated calcium silicates HCS, hydrated calcium aluminates ACH and chloroaluminates. At the time of 1 day and 3 days, we observe the same peaks, but they are more extensive in the presence of metakaolin. This is due to the progress of the pozzolanic reaction. Normally, these peaks will spread over time for paste containing metakaolin until they become flat, a sign of $\mathrm{Ca}$ $(\mathrm{OH})_{2}$ consumption and increased CSH. This clearly shows the reactive effect of metakaolin at a very young age.

\subsection{Density of dried and wet mortars}

The evolution of the density of mortar specimens kept in a dry room is illustrated in Figure $5 \mathrm{a}$. The density decreases with time for all mortars. That of dried mortars containing metakaolin is smaller than that of control mortars at different ages. The loss of mass obtained due to the departure of water by drying is of the order of $3 \%$.

Figure $5 \mathrm{~b}$ shows the evolution of the density of wet mortar specimens kept in water according to their age. The density increases with time for all mortars.

It is shown that the mortars kept in the water gain weight compared to the dried mortars, sign that the water tends to occupy the voids of the cement paste: those caused by the air occluded at the setting up and the voids produced by the contraction due to the hydration of the cement.

Moreover, the density of the mortars containing the metakaolin is reduced compared to that of the control mortars at all the ages. The reduction is around $2 \%$. The loss of mass of dried or wet mortars stored in water is due to the fact that the density of metakaolin substituted to cement is smaller than that of cement.

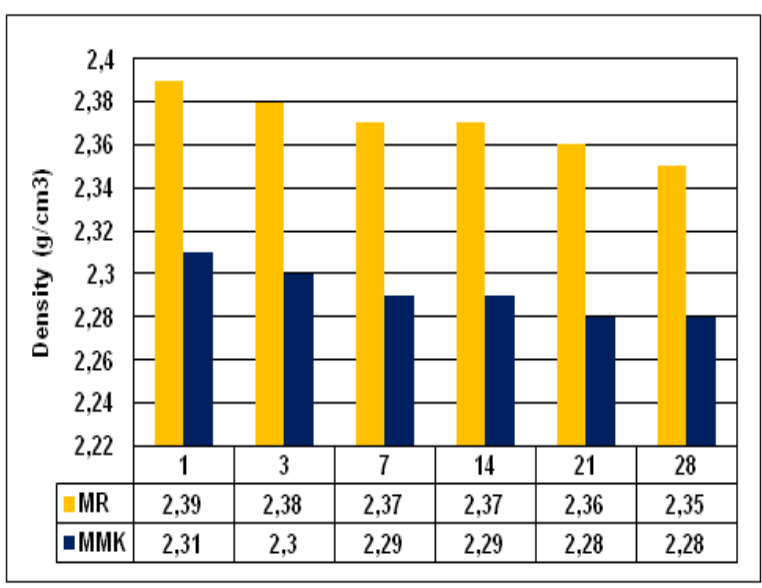

(a)

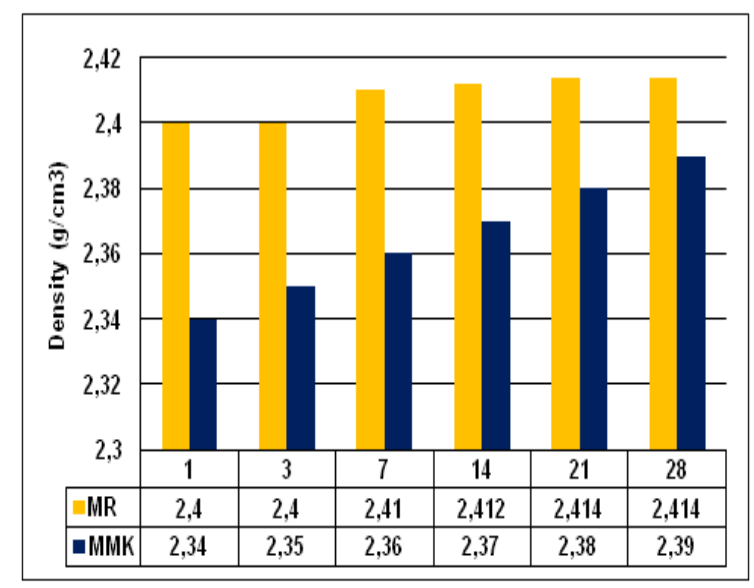

(b)

Fig. 5. Evolution of the density of (a) - Dried mortars, (b) - Wet mortars.

\subsection{Compressive strength of dried and wet mortars}

The development of mechanical strengths of wet mortars with and without metakaolin tested on specimens after a water cure at 1, 3, 7, 14, 21 and 28 days is shown in Figure 6a.

The compressive strengths of the mortars increase rapidly to 14 days of age when they reach their maximum values (91.062 MPa for the control mortar MR, 83.625 MPa for the mortar with 
the metakaolin MMK). At 21 days, a decrease of strength is marked but the latter increase again to 28 days.

Moreover, the incorporation of the metakaolin MK causes a decrease of the mortars strength compared to those of the control mortars and this, at all ages. The reduction is $3 \%, 14.5 \%, 8.4 \%$, $8 \%, 10 \%$ at $1 d, 3 d, 7 d, 14 d, 21 d$, respectively.

But at 28 days, compressive strengths of mortars with or without metakaolin are almost aligned, since the reduction is $5 \%$.

The rate of development of the strength of the control mortar depends mainly on the rate of hydration of the clinker whereas it depends on the combination of the hydration of the cement and the pozzolanic reaction (Pavlíková et al., 2009; Ambroise et al., 1994; Siddique and Klaus, 2009) for a mortar of cement containing the metakaolin. Here, the effect of these is well shown.

Similarly, in Figure 6b, it is shown that for the dried mortar specimens, their compressive strengths develop increasing but do not exceed those of the control mortars regardless of the age of the specimens.

The reduction is $13 \%, 25 \%, 19 \%, 9 \%, 14 \%$, and $9 \%$ at $1 \mathrm{~d}, 3 \mathrm{~d}, 7 \mathrm{~d}, 14 \mathrm{~d}, 21 \mathrm{~d}$, and 28 days respectively. The lowest reduction (9\%) is achieved at 28 days.

In addition, it should be noted that the compression strengths of mortars tested after a water cure at different ages are higher than those of dried mortars. So the water cure promotes the rapid increase of compressive strengths.

The reduction of compressive strengths is due to the fact that the main minerals of the cement which contribute to increase the strengths $\mathrm{C}_{3} \mathrm{~S}$ and $\mathrm{C}_{2} \mathrm{~S}$ decreased since the quantity of cement replaced metakaolin decreased. In addition, the obtained metakaolin may react slowly before 28 days, but its positive effect on mechanical strengths may be shown in the long term.

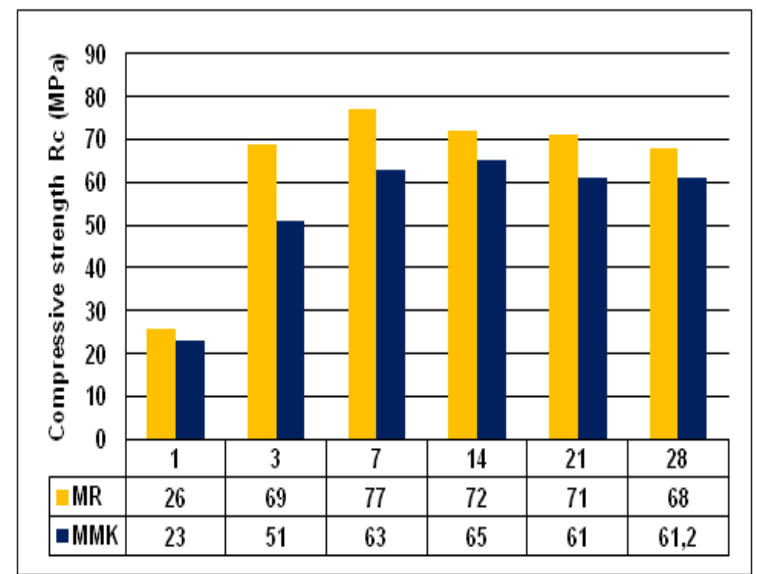

(a)

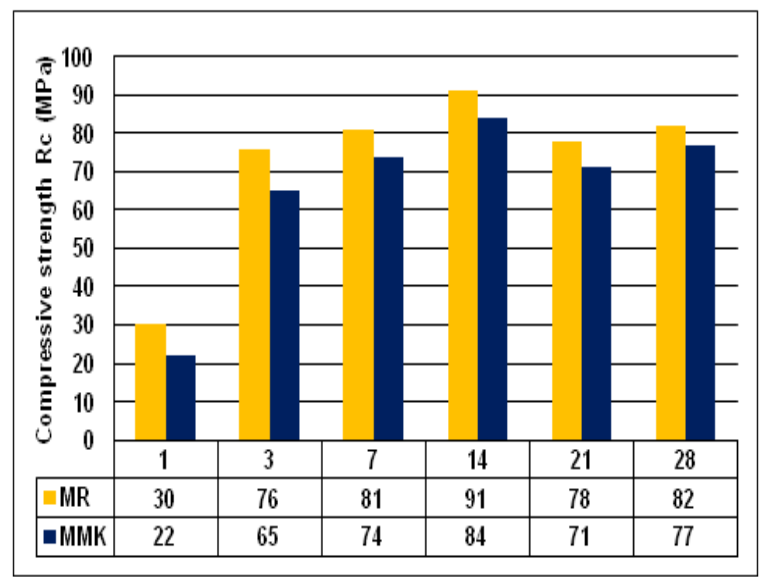

(b)

Fig. 6. Compressive strength of (a) - Dried mortars, (b) - Wet mortars.

\subsection{Flexural strength of dried and wet mortars}

The evolution of flexural strengths of dried and wet mortars preserved in water is shown in Figures $7 \mathrm{a}$ and $7 \mathrm{~b}$. The flexural strengths of the mortars containing the metakaolin are very interesting in the sense that they develop increasing without exceeding those of the control mortar but at 28 days, they get closer.

The reduction is $17 \%, 13 \%, 17 \%, 10 \%, 12 \%$ and $9 \%$ for wet mortars and $20 \%, 13 \%, 17 \%, 6 \%$, $8 \%$ and $5 \%$ for dried mortars at maturity $1 \mathrm{~d}, 3 \mathrm{~d}, 7 \mathrm{~d}, 14 \mathrm{~d}, 21 \mathrm{~d}$ and 28 days respectively. The 
lowest reduction is obtained at 28 days. In addition, the flexural strengths of dried mortars are lower than those of mortars kept in water.

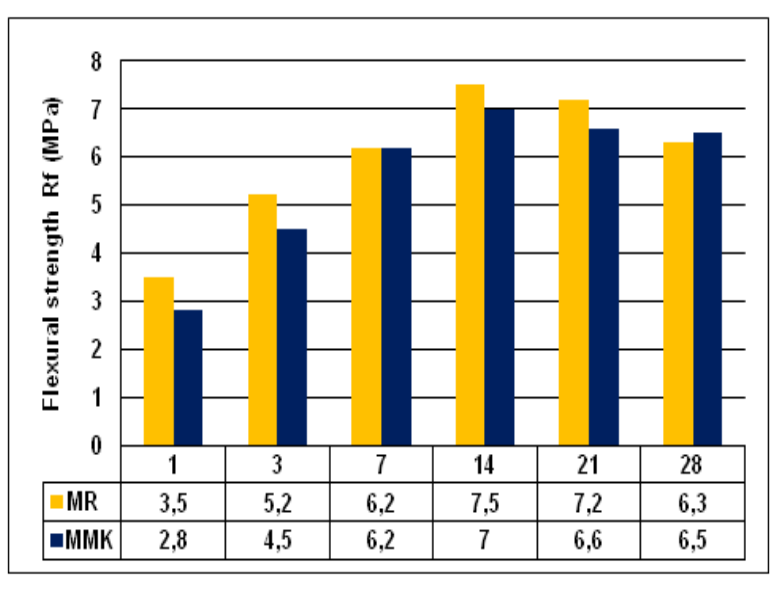

(a)

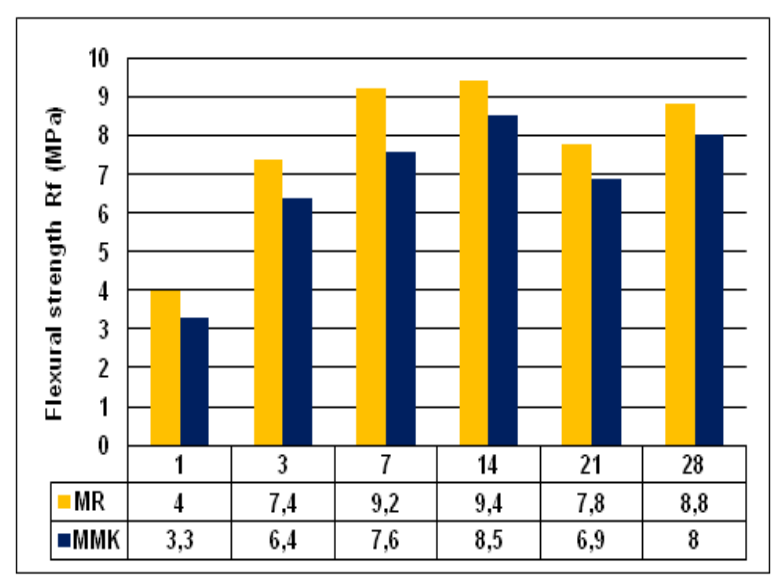

(b)

Fig. 7. Flexural strength of (a) - Dried mortars, (b) - Wet mortars

\section{Conclusions}

Based on the investigation of elaborate mortar mixtures incorporating $10 \%$ rate of metakaolin, the following conclusions are drawn:

- The high levels of $58.32 \%$ silica $\mathrm{SiO}_{2}$ and $35.36 \%$ alumina $\mathrm{Al}_{2} \mathrm{O}_{3}$ contained in the metakaolin favored the pozzolanic reaction and contributed to the development of the mechanical strengths of the mortar particularly at 28 days.

- The substitution of cement by $10 \%$ of metakaolin has a beneficial effect on the cement matrix because it contributes to the densification of the hardened paste by the consumption of portlandite and the formation of the gel of CSH silicates and hydrated calcium aluminates $\mathrm{CAH}$.

- The incorporation of metakaolin as a substitute to cement has led to a slight decrease in compressive and flexural strengths of mortars, especially at 28 days, whatever the state of conservation : in the dry state or after a water cure.

- The reduction of compressive strength $\mathrm{Rc}$ is $5 \%$ and $9 \%$ for mortars containing metakaolin preserved in water and dried respectively.

- The Rf flexural strengths of mortars containing metakaolin are very interesting. At 28 days, $\mathrm{Rf}$ aligns with that of the control mortar.

- The smallest relative difference of $\mathrm{Rf}$ is $9 \%$ for wet mortars and $5 \%$ for mortars dried at 28 days of age.

- The compressive and flexural strengths of mortars tested after a water cure at different ages are higher than those of dried mortars.

- The introduction of $10 \%$ metakaolin decreases the density of dried mortars and increases the density of wet mortars. This is due to the high water absorption of metakaolin. The density is always lower than that of the control mortar. The reduction is low, around $2 \%$.

Moreover, the mechanical strengths are sufficient to classify the elaborated mortars incorporating $10 \%$ of metakaolin as high performance mortars. 
From an environmental point of view, the use of metakaolin as a cement substitution is potential because it allows the reduction of the direct release of gases by the greenhouse effect since there is a decrease in the quantity of cement manufactured.

From an economic point of view, the metakaolin is beneficial since it can replace a quantity of cement with a high manufacturing cost.

Finally, this experimental work paves the way for the use of calcined Kaolin from the Jijel region as a pozzolanic material in the cement industry to improve the physico-mechanical properties and durability of cementitious materials.

\section{References}

Ambroise, J., Maximilien, S., \& Pera, J. (1994). Properties of metakaolin blended cements. Advanced Cement Based Materials, 1(4), 161-168.

Ambroise, J., Murat, M., \& Pera, J. (1986). Investigations on synthetic binders obtained by middletemperature thermal dissication of clay minerals. Silicates Industries,7(8), 99-107.

Badogiannis, E., Kakali, G., Dimopoulou, G., Chaniotakis, E., \& Tsivilis, S. (2005). Metakaolin as a main cement constituent. Exploitation of poor Greek kaolins. Cement and Concrete Composites, 27(2), 197-203.

Kostuch, J. A., GW, W., \& TR, J. (2000). High performance concretes containing metakaolin. A Rview concr, $21,799-811$.

Madandoust, R., \& Mousavi, S. Y. (2012). Fresh and hardened properties of self-compacting concrete containing metakaolin. Construction and Building Materials, 35, 752-760.

Mansour, M. S., Abadlia, M. T., Afalfiz, A., \& Ladaoui, W. (2013). Reologia zapraw i betonów z dodatkami mineralnymi. Cement Wapno Beton, 18(80, nr 5), 264-270.

Mansour, M. S., Abaldia, M.T., Jauberthie, R., \& Messaoudenne, I. (2012). Metakaolin as a pozzolan for high performance mortat.. Cement. Wapno. Beton. 2 : 102-108.

Merabet, D., \& Belkacemi, H. (2003, September). Caractérisation minéralogique et chimique du kaolin de Tamazert (Algérie). In Annales de Chimie Science des Matériau, 28(5), 61-83.

Pavlíková, M., Brtník, T., Keppert, M., \& Černý, R. (2009). Effect of metakaolin as partial Portland-cement replacement on properties of high performance mortars. Cement Wapno Beton, 3, 115-122.

Poon, C. S., Lam, L., Kou, S. C., Wong, Y. L., \& Wong, R. (2001). Rate of pozzolanic reaction of metakaolin in high-performance cement pastes. Cement and concrete research, 31(9), 1301-1306.

Rojas, M. F., \& Cabrera, J. (2002). The effect of temperature on the hydration rate and stability of the hydration phases of metakaolin-lime-water systems. Cement and concrete research, 32(1), 133138.

Sabir, B. B., Wild, S., \& Bai, J. (2001). Metakaolin and calcined clays as pozzolans for concrete: a review. Cement and concrete composites, 23(6), 441-454.

Sayanam, R. A., Kalsotra, A. K., Mehta, S. K., Sing, R. S., \& Mandal, G. (1989). Studies on thermal transformations and pozzolanic activities of clay from Jammu region (India). Journal of Thermal Analysis,35, 9-106.

Siddique, R., \& Klaus, J. (2009). Influence of metakaolin on the properties of mortar and concrete: A review. Applied Clay Science, 43(3-4), 392-400.

Tafraoui, A., Escadeillas, G., Lebaili, S., \& Vidal, T. (2009). Metakaolin in the formulation of UHPC. Construction and Building Materials, 23(2), 669-674. 